\title{
Pharmacognostic, Phytochemical and Antioxidant Studies of Hydnophytum formicarum L.
}

Fatiha EL Babili*, Amandine Guillouty², Halova-Lajoie Barbora ${ }^{3}$, Caroline Vincent ${ }^{4}$ and Nathalie Sejalon-Delmas ${ }^{1,5,6}$

${ }^{1}$ Jardin Botanique Henri Gaussen, Université Paul Sabatier, Toulouse III - 2 rue Lamarck 31400 Toulouse, France

${ }^{2}$ Faculté des Sciences Pharmaceutiques - UPS Toulouse III - 35 Chemin des Maraîchers 31062 Toulouse, France

${ }^{3}$ Laboratoire de Chimie Bioinorganique Medicale LU 07, Universite Paul Sabatier, 118 Route de Narbonne Bat. $3 S C, 31062$ Toulouse, France

${ }^{4}$ Ecole Prératoire de Chimie, Lycée d'Enseignement Général 26, bd Déodat de Séverac - 31076 Toulouse, France

${ }^{5}$ Laboratoire de Recherche en Sciences Végétales (LRSV), Université de Toulouse, UPS, CNRS, 31326 Castanet-Tolosan, France

${ }^{6} E C O L A B$, Université de Toulouse, CNRS, INPT, UPS, France

\begin{abstract}
The leaves of Hydnophytum formicarum Jack belonging to the family Rubiaceae, a tropical tree commonly found in eastern and southern Thailand, South Asia, Papua New Guinea and the Pacific Islands, were studied for these antioxidant compounds. Sterols, flavonoids and phenolic compounds appear to be good markers for this species. Chromatographic and histochemical techniques were used to analyze its secondary metabolites and to localize these molecules in the leaves of $H$. formicarum and its petiole. With histochemistry, we can locate the phenols in situ by an iron chloride reagent, which gives a black color, especially in fibers, hypodermis and xylem. Flavonoids are detected histochemically using a potassium hydroxide reagent to obtain a yellow coloration under visible light. Histochemical studies of $H$. formicarum showed a high concentration of natural antioxidants in the central cylinder, particularly in the vascular bundle, whereas condensed catechic tannins were mainly detected in collenchyma, fibers and also in xylem. The high levels of phenolic compounds and their localization in the conductive tissues allow us to explain the traditional medicinal use carried out in Thailand with this tree because, very often, compounds with antioxidant properties prove to be good anti-cancer agents.
\end{abstract}

Keywords: Hydnophytum formicarum; Phenols; Antioxidants; Histolocalization

\section{Introduction}

After the immense infatuation that modern allopathy has succeeded, a strong return of interest for traditional medicine is noted. People increasingly want to know something about the plants that surround them and especially their ancient medicinal uses.

On the other hand, the rising concern for the preservation of our environment and the rejection of drugs, having too many undesirable effects, pushes plant remedies to the front of the stage. Plant drugs are gradually regaining their important role, through food supplements, in preserving health in both underdeveloped and industrialized countries. The plant is indeed a true chemical factory of both primary and secondary metabolites. It is these latter who are often involved in the biological properties of plants that man has always known to exploit in health service, in other things. Screenings of the aqueous or alcoholic drugs extracts are systematically carried out for the plants used traditionally in order to confirm and corroborate or invalidate the traditional uses described. From this, a phytochemical study can be initiated in order to locate the most active fraction of this anticancer plant and its chemical profile. To carry out this work, a precise botanical identification (morphological and anatomical) is necessary in order to avoid any mistake that could have serious consequences, as was the case in losing products. For this, our work focuses on the botanical, phytochemical and biological study of the leaves of a medicinal myrmecophyte called Hydnophytum formicarum.

Hydnophytum formicarum (Jack) is part of the epiphytic Rubiaceae family, found in Southeast Asia (Borneo, Java, Malaysia). It can reach $50 \mathrm{~cm}$ and is provided with its stem base bulge also called "caudex", which is wide and has orifices that can house ants.

Its leaves, few and much spaced on the stem, are supple and of a light green colour. The odourless flowers, blooming in spring, are small $(<1 \mathrm{~cm})$, white, sessile, generally grouped in the axils of the leaves. The flowers evolve in a few weeks in fleshy, orange fruits, containing only a few seeds that can germinate quickly.

\section{Materials and Methods}

\section{Plant material}

Leaves were collected from the investigated plant species grown in the tropical greenhouse of the botanical garden Henri Gaussen. Study of morphology and anatomy foliar were identified by C. Chatelain and F. EL Babili and voucher specimen were deposited at the herbarium of the botanical garden Henri Gaussen.

\section{Preparing slides}

Observations are based on microscopic studies of sectioned and stained material of tissues transverse sections are prepared with a sliding microtome (MSE) and stained in alun carmine-green combination or Mirande reagent [1] during 2 to 3 minutes then washed with water. Following staining, the transverse sections are mounted on glass slides using glycerine gel. Powder observations were made using Chloral hydrate solution R [2]. Observations were made with a LEICA Microsystems DMLB microscope, and pictures were taken with Digital Camera Power Shot S40 CANON photo-micrographic system. For the description we have used some help books [3-5].

*Corresponding author: Fatiha EL Babili, Jardin Botanique Henri Gaussen Université Paul Sabatier, Toulouse III-2 rue Lamarck 31400 Toulouse, France, Tel: +33561556611; E-mail: fatiha.el-babili@univ-tlse3.fr

Received October 07, 2016; Accepted October 17, 2017; Published October 23, 2017

Citation: Babili FE, Guillouty A, Barbora HL, Vincent C, Sejalon-Delmas N (2017) Pharmacognostic, Phytochemical and Antioxidant Studies of Hydnophytum formicarum L. Med Chem (Los Angeles) 7: 276-284. doi: 10.4172/2161 0444.1000468

Copyright: $\odot 2017$ Babili FE, et al. This is an open-access article distributed under the terms of the Creative Commons Attribution License, which permits unrestricted use, distribution, and reproduction in any medium, provided the original author and source are credited. 


\section{Anatomical analysis}

The dry materials were divided into appropriate sizes. Samples of leaf were sectioned on a microtome in slices thick. Tissues were stained by alun carmine-green combination or Mirande reagent and finally mounted on glass slides using glycerine gel for observation. Some sections were not stained so that idioblasts and other deposits would not be destroyed or otherwise altered during processing. The samples of crude drug were powdered. Ten different slides from the same powder were observed. Microchemical reactions were applied with lactic reagent or Gazet reagent [6]. To study powders in order to reveal lignified elements such as wood fibres, sclerenchyma and calcium oxalate crystals. All representative microscopic features were recorded by colour photography.

\section{TLC analysis}

An aliquot of methanol extract of Hydnophytum formicarum (40 $\mu \mathrm{L}$ ) was directly deposited (as spots or bands) onto the TLC plates. TLC plates were developed in a pre-saturated solvent chamber with toluene-ethyl acetate-formic acid-methylene chloride (10:12:6:12) as developing reagents until the solvent front reached $1 \mathrm{~cm}$ from the top of plates. The developed TLC plates were then removed from the chamber, and allowed to air-dry for $30 \mathrm{~min}$. Each TLC plate was then monitored under visible and UV light at 254 and $366 \mathrm{~nm}$.

\section{Histolocalisation of metabolite studied on the leaves section}

On the basis of histochemical reactions due to the interaction between specific reagents and cellular metabolites, it is possible to carry out in situ qualitative analyses on the metabolites of interest present in the tissue of the plant under study. For this we have been inspired by the work on thin-layer chromatography of "Plant Drug Analysis: A Thin Layer Chromatography Atlas" [7]. To demonstrate the presence of various metabolites in the plant tissue of the plant studied, we proceeded as follows:

Freehand cross sections on the leaves and petioles of Hydnophytum formicarum will be after a dehydration and degassing step in an alcoholic bath, diving (reaction time specific to each analysis) in a reactive bath and then mounted between slide and cover slip in glycerine gelatine (50:50, v/v) solution. The histochemical examination was made under a Novex B-Series HOLLAND microscope. Photographs were taken with a digital camera OPTIKAMB5 (SN417922) equipped with an ocular micrometer.

The transverse sections of Hydnophytum formicarum were subjected to reaction with specific reagents, according to the different groups of metabolites to be investigated: lipids and essential oils, Soudan III [8]; alkaloids, Dragendorff reagent [9]; terpenes, Phosphomolybdic acid [10]; starch, Iodine-potassium and Lugol reagent [8]. For all histochemical stains matched, controls on the samples slides without any treatment (blanks) were also mounted.

Tannins: Tannins are detected by hydrochloric acid reagent $(37 \%$ VWR Prolabo). The sections were placed for $10 \mathrm{~min}$ in this reagent. The tannins are coloured red brown.

Lipids: The sections were placed for $5 \mathrm{~min}$ in Soudan III reagent (Begenat) and mounted between slide and cover slip. They were observed under light microscope. Lipids colour is bright red.

Gums: Gums are detected by Harris Hematoxylin solution (SigmaAldrich). The sections were placed for $15 \mathrm{~min}$ in this reagent. The Gums are coloured violet.
Sugars: The leaf sections are immersed in sulfuric acid (95\% VWR Prolabo) thymol reagent for 5 min with heating and then placed between slide and cover slip. They were observed using a microscope. The sugars are pink colour.

Phenols: Phenols are detected by iron chloride reagent $(0.2 \mathrm{M}$ in 2-methyltetrahydrofuran - Sigma Aldrich). The sections were placed for $5 \mathrm{~min}$ in this reagent. The tannins are coloured blue-black, the phenols are coloured green-black, the flavonoids are green and pyrogallol is coloured red or blue.

Starch: Starch is detected by iodine or Lugol reagent (Jeulin). The sections were placed for $2 \mathrm{~min}$ in this reagent. The starches are coloured blue-black.

Flavonoids: The leaf sections are immersed in potassium hydroxide reagent (HKO Sigma Aldrich) for $5 \mathrm{~min}$ and then placed between slide and cover slip. They were observed using a microscope. The flavonoids are yellow.

Coumarins: Coumarins are detected by ammoniac or potassium hydroxide reagent (HKO was purchased from Sigma-Aldrich). The sections were placed for $5 \mathrm{~min}$ in these reagents. Coumarins are coloured bright yellow.

Catechic tannins: Tannins are detected by hydrochloric acid reagent. The sections were placed for $10 \mathrm{~min}$ in this reagent. Tannins are coloured red brown.

Alkaloids: For alkaloids, transverse sections were immersed (15 min) in Dragendorff's reagent (spray solution was purchased from Merck) and then placed between slide and cover slip. Specimens were examined under visible light using a microscope. Alkaloids were reddish-brown to orange colour.

Terpenes: The dehydrated leaf sections are immersed in phosphomolybdic acid reagent (was purchased from Sigma-Aldrich Fluka) for $5 \mathrm{~min}$ and then placed between slide and cover slip. They were observed using a microscope. The terpenes are black on yellow background.

Essential oil: Essential oil is detected by Soudan III or Chloral hydrate reagent (99\% was purchased from Sigma-Aldrich). The sections were placed for $5 \mathrm{~min}$ in these reagents, without or with heating, respectively. Essential oil is coloured orange brown or red, respectively.

Iridoides: The leaf sections immersed in distilled water mixed with hydrochloric acid reagent $(12 \mathrm{~N})$ and heated in a water bath for $30 \mathrm{~min}$ and then placed between slide and cover slip. They were observed using a microscope. The iridoides are blue.

Carotenoides: The leaf sections are immersed in Lugol reagent for $5 \mathrm{~min}$ and then placed between slide and cover slip. They were observed using a microscope. The carotenoides are green-blue.

Heterosides cardiotonic: The leaf sections are immersed in RAYMOND reagent to which will be added 5 drops of $\mathrm{KOH}$ for $5 \mathrm{~min}$ and then placed between slide and cover slip. They were observed using a microscope. Cardenolides are fugitive violet and lactone blue. With the KEDGE reagent the heterosides are stable red.

Antioxidants: Antioxidants are detected by DPPH reagent was purchased from Sigma-Aldrich). The sections were mounted directly in the reagent. Essential oil is coloured orange brown or red, respectively. Transverse sections are examined directly under a photonic microscope in order to locate the areas of discoloration on the violet background. 


\section{TLC bioautography method [11]}

An aliquot of aqueous and methanol extracts of the plant $(40 \mu \mathrm{L})$ was directly deposited (as spots or bands) onto silica gel 60F254 TLC plates (was purchased from Merck, Germany). TLC plates were developed to a distance of $75 \mathrm{~mm}$, in a $20 \mathrm{~cm} \times 20 \mathrm{~cm}$ glass flat-bottom chamber after equilibration with mobile phase vapour for $30 \mathrm{~min}$ with ethyl acetateformic acid-acetic acid-water (100:11:11:26) as developing reagent. The developed TLC plates were then removed from the chamber and airdried in an aerator at room temperature. The plates were then colorized by spraying with $0.04 \%$ DPPH-methanol solution $(20 \mathrm{mg}$ DPPH dissolved in $50 \mathrm{~mL}$ methanol) for $5 \mathrm{~s}$. and heated at $40^{\circ} \mathrm{C}$ on a plate heater for $30 \mathrm{~min}$. Extracts antiradical activity were estimated from the intensity of disappearance of the violet/purple background of the plate. Free radical scavenging zones were qualitatively identified immediately as yellow areas against a light violet/purple background. Each TLC plate was then monitored under Visible light and photographed. The plates were then colorized by spraying Dragendorff reagent for $5 \mathrm{~s}$. and air-dried in an aerator at room temperature.

\section{Methods for assessing the presence of antioxidants in plants}

The free radical test DPPH • (2,2-DiPhenyl-1-PicrylHydrazyl) is used. 2,2-Diphenyl-1-picrylhydrazyl is a stable free radical which acts by combining with other free radicals. This compound was one of the first free radicals used to study the structure-activity relationship of phenolic compounds. This is a widely used test because it is simple and relatively reliable. DPPH is a black powder made up of stable free radical molecules. This is soluble in methanol or ethanol. This radical has a free electron on an atom of the nitrogen bridge. The delocalization of this electron results in the blue-violet coloration characteristic of the reagent. When DPPH reacts with an antioxidant, a hydrogen atom is attached to the radical, resulting in loss of colour. This is what makes it possible to measure the effectiveness of an antioxidant and that the reaction can be followed by spectrophotometry between 515 and 518 $\mathrm{nm}$.

\section{Preparation of the DPPH solution}

Preparation of the DPPH solution [12]: $3.7 \mathrm{mg}$ of DPPH powder are diluted in $25 \mathrm{ml}$ of methanol, resulting in a concentration of 375 $\mathrm{mM}$. The powder must be prepared in advance and the solution must be well agitated because solubilisation is difficult. The solution can be stored for only a few days in the freezer.

\section{Preparation of the extract}

$50 \mathrm{mg}$ of dried plant powder are extracted in $100 \mathrm{ml}$ of ethanol heated to $50^{\circ} \mathrm{C}$. The solution is left to stand for half an hour. The solution is then filtered using a funnel and a filter paper and then evaporated under reduced pressure at $40^{\circ} \mathrm{C}$. to $175 \mathrm{mbar}$. The extract obtained is then diluted in $25 \mathrm{ml}$ of methanol and the mother solution S1 is thus obtained. The stock solution contains $50.3 \mathrm{mg}$ of plant powder in $25 \mathrm{ml}$ of methanol. The concentration is therefore $2.010 \mathrm{mg} / \mathrm{ml}$. In the test, when $1 \mathrm{ml}$ of methanol is mixed with $1 \mathrm{ml}$ of S1 solution and $1 \mathrm{ml}$ of DPPH and an immediate discoloration is observed, the stock solution must be diluted: $10 \mathrm{ml}$ of solution $\mathrm{S} 1$ are introduced into a $100 \mathrm{ml}$ graduated flask and the mixture is made up with methanol. Then, for extract to be analysed, we carried out tests including $1 \mathrm{ml}$ of methanol, $1 \mathrm{ml}$ of test solution and then $1 \mathrm{ml}$ of DPPH. This preparation is then put into obscurity for the time the reaction takes place.

\section{Measure of absorbance and absorbance reduction measurements}

The absorbance is measured at the end of the reaction; it is carried out at $517 \mathrm{~nm}$. According to the results, the dilution range is adjusted in order to obtain a curve reflecting the percentage of DPPH consumed relative to the concentration. Indeed, when the solution reacts immediately, it is necessary to dilute the solution in methanol because it means that all the DPPH has reacted immediately. Conversely, when the absorbance remains the same throughout the reaction, this means that the solution is too diluted. We carried out a kinetic curve in order to estimate the reaction time of the solution to be analysed with the DPPH. The leaves were picked and then dried for at least a week. They were then reduced to powder by means of a mortar and a pestle. The powder was then extracted with methanol. This extract is analysed by the absorption spectrometer. It has been seen previously that, in the presence of an antioxidant, the DPPH radical is reduced: a discoloration of the solution is observed. The decay of the absorbance is measured by spectrophotometry and corresponds to the decrease in the concentration of the DPPH radical. The results of the absorbance reduction measurements $\left(\mathrm{IC}_{50}\right)$ can be represented as a percentage:

\%DPPH consumed=1-(Absorbance in the presence of antioxidant/Absorbance without antioxidant $) \times 100$

Antioxidant activity of extracts was expressed as $\mathrm{IC}_{50}$, defined as the concentration of the test material required to cause a $50 \%$ decrease in initial DPPH concentration. Ascorbic acid was used as a standard. All measurements were per-formed in triplicate.

\section{Statistical analysis}

All data were expressed as means \pm standard deviations of triplicate measurements. The confidence limits were set at $\mathrm{P}<0.05$. Standard deviations (SD) did not exceed $5 \%$ for the majority of the values obtained.

\section{Monograph (Hydnophytum formicarum)}

\section{Elements of botany}

Scientific name: Hydnophytum formicarum Jack (Figure 1) belongs to the family Rubiaceae. The size of the plant is generally 10 to $50 \mathrm{~cm}$ in height. It has small oval sessile leaves. The cavities in the tuber allow the absorption of water and essential nutrients from fecal matter and debris brought by the ants. In return, plants provide food for ants

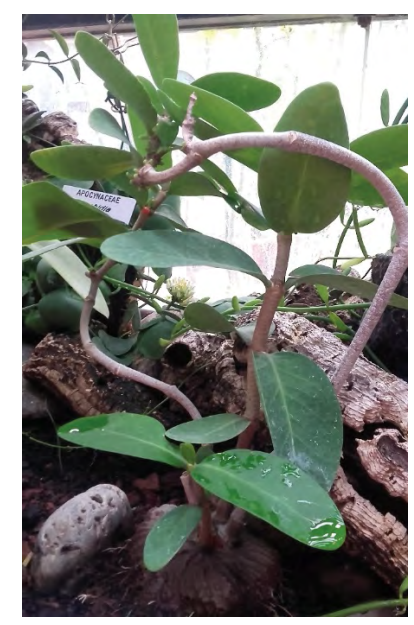

Figure 1: Hydnophytum formicarum 
with high-protein nectar. This plant is commonly found in eastern and southern Thailand, Southeast Asia, Papua New Guinea and the Pacific Islands.

\section{Used part}

The caudex is used in Thailand.

\section{Available monographs}

Hydnophytum formicarum Jack is used in traditional Thai medicine for treatment of cancer.

\section{Chemical constituents [13]}

The $H$. formicarum extract reveals different flavonoids and phenolic compounds by UV and NMR detection (stigmasterol: 1, isoliquiritigenin: 2, protocatechualdehyde: 3, loot: 4 and butein: 5) (Figure 2).

\section{Dosage forms or forms of traditional uses}

Myrmecophilic medicinal plant commonly found in eastern and southern Thailand, Southeast Asia, Papua New Guinea and the Pacific islands. Its caudex has cardiovascular, anti-inflammatory and ant parasitic activities. It is used for the relief of rashes and as neurotonic for the treatment of headache, hepatitis, rheumatism and diarrhea.

It has long been used in Thai medicine in combination with other plant extracts for the treatment of diabetes. However, no isolation and characterization were performed. It would inhibit xanthine oxidase [14]. Its ant proliferative activity against human HT-1080 fibro sarcoma cells has been described [13].

\section{Pharmacology research work}

One study evaluated the antimicrobial and antioxidant activity of the plant [13]. Indeed, the extracts of the swollen hypocotyl (wrongly referred to as tuber) with hexane, dichloromethane, ethyl acetate and methanol are all effective against the bacterium Corynebacterium diphtheriae with a minimum inhibitory concentration of $256 \mu \mathrm{g} / \mathrm{ml}$.

Other microorganisms such as Staphylococcus aureus, Shigella dysenteriae, and Streptococcus pyogenes are inhibited by ethyl acetate extract. The butin is very active against Plesiomonas shigelloides with a minimum inhibitory concentration of $60 \mu \mathrm{g} / \mathrm{ml}$. In comparison, ampicillin inhibits it at a concentration of $10 \mu \mathrm{g} / \mathrm{ml}$. This makes this plant an interesting antimicrobial. These same extracts are studied for their antioxidant properties with the DPPH test.

The extracts are diluted and then placed in the dark for 30 minutes. The results are positive for each of them, with moderate to high antioxidant power except for the hexane extract which has a low antioxidant power over the others.

The reference molecule is $\alpha$-tocopherol. For example, the extract, acetate has an EC50 $=8.40 \mu \mathrm{g} / \mathrm{ml}$ and $\alpha$-tocopherol has an EC50 $=6.67$ $\mu \mathrm{g} / \mathrm{ml}$. It is therefore a strong antioxidant potential. Another study showed that the ethanolic extract of the swollen hypocotyl had an effect on T47D tumor cells by inhibiting their proliferation. Indeed, the alcoholic extract of the bulbous hypocotyl shows an inhibition of $53.45 \%$ of the T47D cells at a concentration of $100 \mu \mathrm{g} / \mathrm{ml}$. This leads to the conclusion that Hypnophytum formicarum Jack may have interesting anti-cancer properties $[15,16]$.

$H$. formicarum serves as a potential source for new QS-based antibacterial drugs towards $P$. aeruginosa [17].

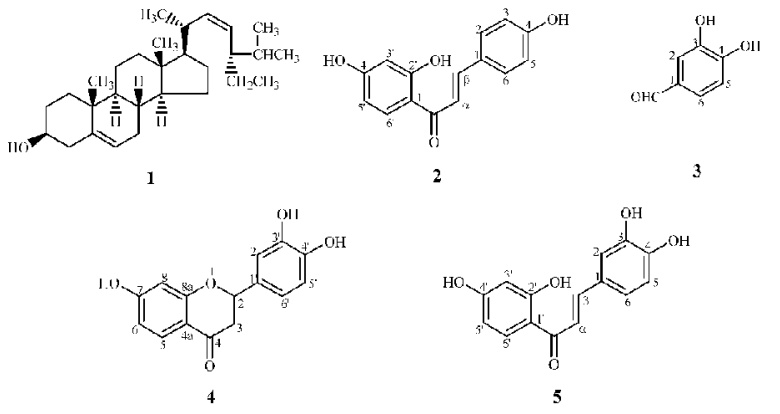

Figure 2: Sterols, flavonoids and phenolic compounds extracted from Hydnophytum formicarum Jack (1).
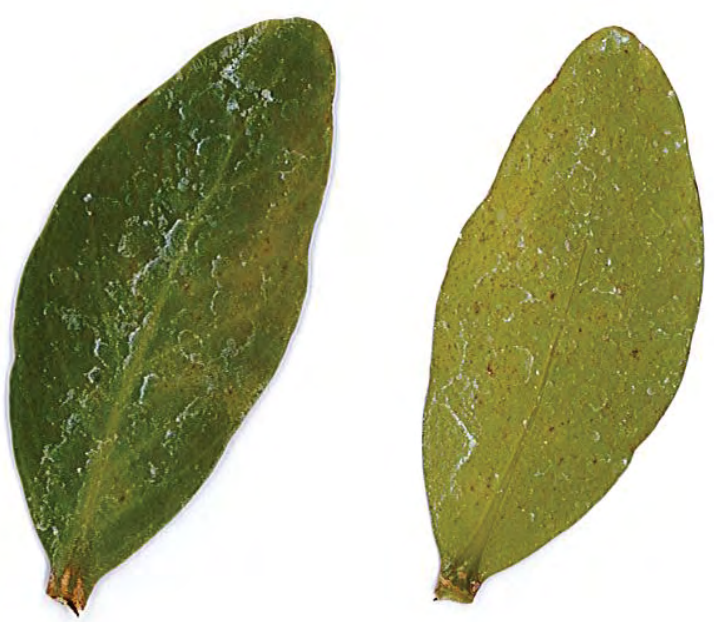

Figure 3: Upper and lower surfaces of the Hydnophytum formicarum leaf.

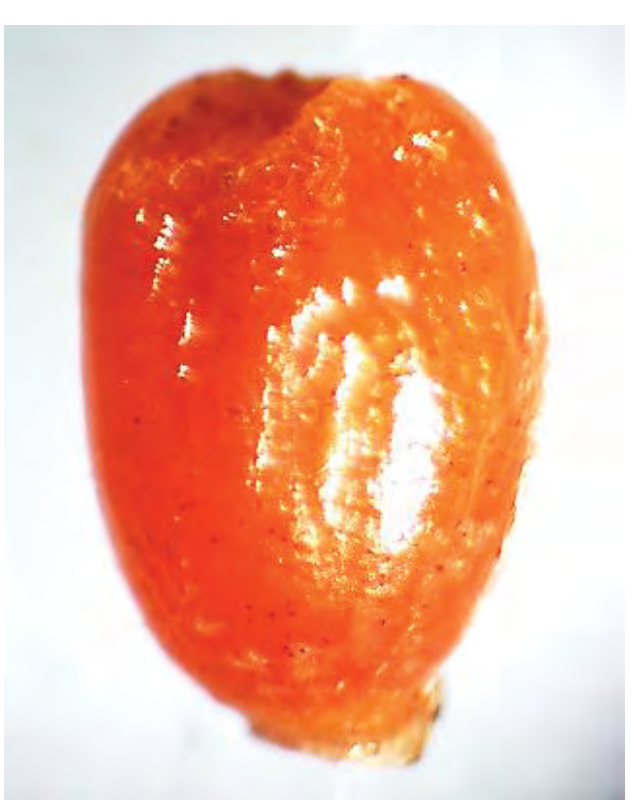

Figure 4: Hydnophytum formicarum fruit (x 2). 
Citation: Babili FE, Guillouty A, Barbora HL, Vincent C, Sejalon-Delmas N (2017) Pharmacognostic, Phytochemical and Antioxidant Studies of Hydnophytum formicarum L. Med Chem (Los Angeles) 7: 276-284. doi: 10.4172/2161-0444.1000468

\section{Toxicology}

No toxicological data have been found in the literature.

\section{Results}

Leaf morphology (Figures 3-5, made using a binocular loupe Euromex StereoBlue with indication of magnification in parenthesis).

Leaf 2.5 times longer than wide at apex and narrow base, rounded apex, margin slightly corrugated. The leaf is sessile, with a main rib projecting over half its length, the nerve is pinnate and the secondary veins are spaced and reach the margin of the leaf blade. A slight network of tertiary ribs appears. The epidermis is covered with a sort of white powder, which is accentuated as soon as the leaf begins to dry. The leaf is thick and is dotted with brownish spots at the lower epidermis. The epidermis is glabrous.

The fruit has an orange pericarp dotted with brownish spots. It contains two oval acuminate seeds, beige in color and striated longitudinally.

\section{Anatomical analysis of Hydnophytum formicarum}

Midrib transverse section (TS): The transverse section of the leaf, almost circular, stained with alun carmine-green combination or Mirande reagent shows various characteristic elements from the outer to the inner side (Figures 6 and 7):

- A cuticularized upper epidermis (greenish coloration) with isodiametric single-layered cells.

- A hypodermis consisting of 1 or 2 layers of rectangular cells.

- A cortical parenchyma with rounded cells separated by intercellular spaces and containing large fibers thick walled with canaliculated walls (blue) and large lumen.

- A complete ring of pericyclic composed with lignified fibres thick walled, with a narrow lumen.

- Phloem is organized in alternating zone with liberian cell walls non-thickened.

- Cambium is not distinct. Xylem is a broad radiate zone composed of vessels and xylem parenchyma. Each xylem patch is separated from its neighbor by large starchy medullary rays.

- A rounded cellular marrow containing large fibers with canaliculated walls.

\section{Lamina transverse section (TS)}

- Upper and lower epidermis similar to that of the median vein with a thick cuticle upper facing and many stomata lower facing (Figure 8). The epidermal cells are isodiametric thin-walled cells.

- A hypodermis with 1 or 2 layers of rectangular cells on both sides showing idioblast containing calcium oxalate acicular crystals or also called raphides.

- A palisade with elongated chlorophyllian cells.

- Secondary vascular bundles.

- A spongy mesophyll containing large canaliculated fibers.

- A hypodermis.

- Many raphides are found on the spongy mesophyll of the midrib.

\section{Histolocalisation of secondary metabolites}

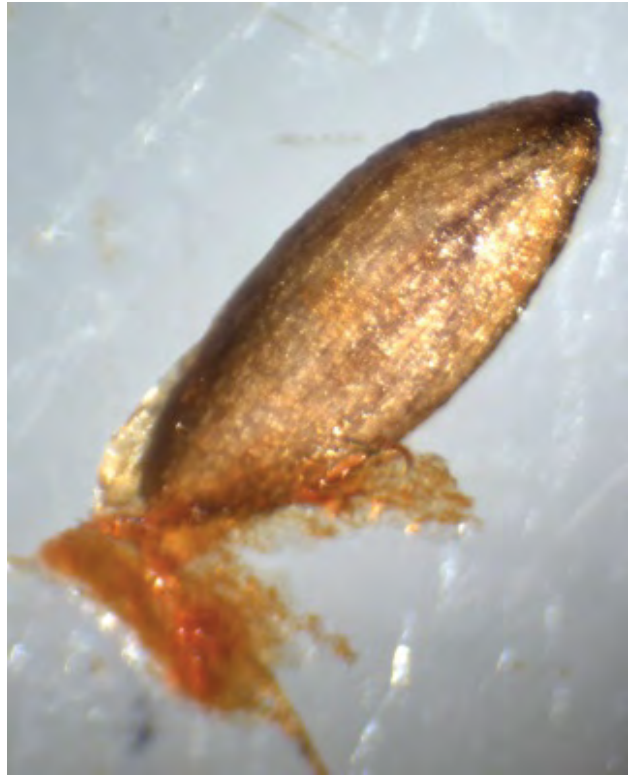

Figure 5: Hydnophytum formicarum seed (x 2).

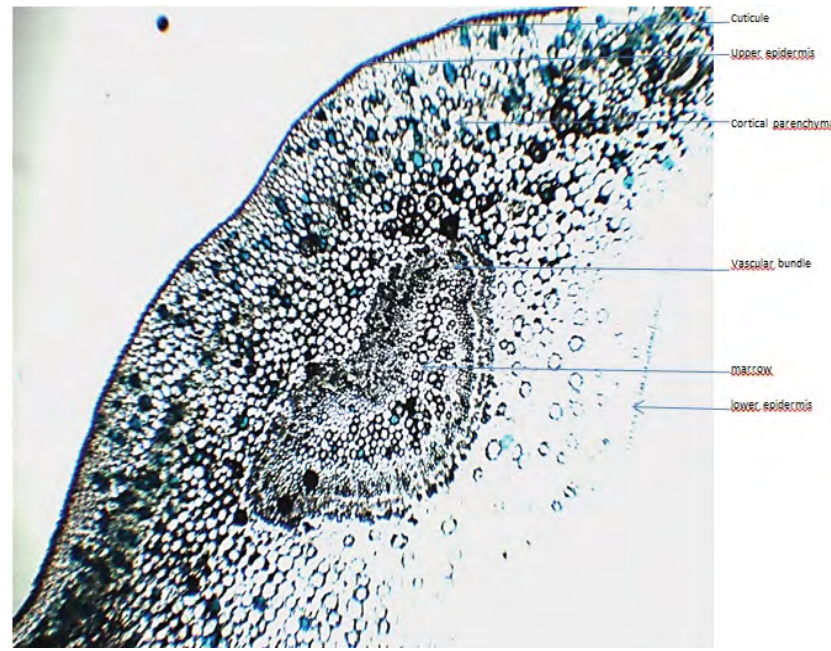

Figure 6: Transverse section of Hydnophytum formicarum leaf (magnification $x$ 4) width (scale bars: $200 \mu \mathrm{m}$ ).

For the histolocalization tests, some cross-sections will be presented, and then the rest of the work will be presented in the form of a summary in Table 1 .

Alkaloids: The phloem reacts positively to the reagent. Thus, a qualitative positive characterization of the alkaloids presence in the liberian zone can be concluded (Figure 9).

The colored zones in orange by Dragendorff reagent make it possible to demonstrate qualitatively alkaloids presence in elaborated sap conductive tissues as well as in the epidermal tissue (Figure 10).

DPPH: The reaction of the sheet cross-section with the DPPH reagent shows an immediate discoloration of the woody zone, which remains greenish, and more generally of the vascular cylinder. As for the bark, the discoloration is slow and gradual. Since the analysis is only quantitative, it is difficult to see a clearly defined area. In conclusion, 
conductive tissues contain substances with antioxidant activities (Figure 11).

Other secondary metabolites studied: Secondary metabolites studied given in Table 1 .

\section{Antioxidant capacities}

TLC combined with DPPH bioautographic assay in situ is the analytical qualitative method we used to choose the plants to study before DPPH assays. In TLC, we can see that the herb studied here exhibit an antioxidant profile. Free radical scavenging zones were identified, qualitatively, immediately as yellow areas against a light violet/purple background. In a second TLC, we begun to explore the complexity of the studied extract, work that will led us to further identification. The mother solution (S1) contains $50.3 \mathrm{mg}$ of Hydnophytum powder in 25 $\mathrm{ml}$ of ethanol. The concentration is therefore $2.010 \mathrm{mg} / \mathrm{ml}$. In the tests, when $1 \mathrm{ml}$ of ethanol is mixed with $1 \mathrm{ml}$ of $\mathrm{S} 1$ solution and $1 \mathrm{ml}$ of $\mathrm{DPPH}$, an immediate discoloration is observed. The $\mathrm{S} 1$ is thus diluted: $10 \mathrm{ml}$ of solution S1 are introduced into a $100 \mathrm{ml}$ graduated flask and the mixture is made up with ethanol. In our study, Hydnophytum formicarum possess strong antioxidant activity. Our last result reveals an $\mathrm{IC}_{50}$ lower than that of the Trolox $\left(\mathrm{IC}_{50}\right.$ of $\left.0.08 \mathrm{mg} / \mathrm{mL}\right)$, which is the reference. The medicinal herb antioxidant activity (Table 2) showed for its ethanolic extract an $\mathrm{IC}_{50}$ of $0.04 \mathrm{mg} / \mathrm{mL}$ in DPPH radical scavenging assay. This approach will guide us in finding the best potential in terms of chemical families and activities searched, knowing that tests remain the safest way. In order to clarify our results, we have carried out an open column chromatography fractionation of the Hydnophytum formicarum ethanolic extract. This work aims to give more details on the type of metabolites responsible for the remarkable antioxidant activity found. Fractionation yielded the following enriched fractions: hexanic, ethyl acetate, chloroform, methanol and water, having an $\mathrm{IC}_{50}$ of $0.08,0.037,0.014,0.056$ and $0.008 \mathrm{mg} / \mathrm{mL}$, respectively.

Given these results, we decide to study chemical composition of the hexane fraction albeit the aqueous fraction which has antioxidant activity 10 times higher for a simple reason for extractive efficiency. Especially since the comparison of their CCM profile shows little difference. Enriched aqueous fraction of Hydnophytum formicarum ethanolic extract (Table 3) contains $459.19 \pm 10.63$ of polyphenols, $30.52 \pm 6.56$ of tannins and $2.08 \pm 0.1 \mathrm{~g} / \mathrm{kg}$ of flavonoids and $0.05 \pm 0.0$ $\mathrm{mg} / \mathrm{kg}$ of anthocyanins. The activity appears therefore correlated to the presence of polyphenols expressed as Gallic acid equivalent essentially, although the tannins are in substantial quantity.

\section{Conclusion}

Thanks to screening by thin layer chromatography and histolocalisation on transverse sections, we have been able to select an extremely interesting plant more easily and less costly among many tropical medicinal plants. The tests with DPPH confirmed our hypothesis as to the leaves and caudex ethanolic extract antioxidant activity of Hydnophytum formicarum. The work on caudex could not be developed since it requires plant destruction. So we concentrated our work on leaves, which are much simpler to obtain in our tropical greenhouse. The spectrophotometric assays of the chemical compositions corroborate the qualitative analytical results obtained by histolocalisation of metabolites of interest. Indeed, by studying Table 1 , we find the presence of phenols, flavonoids and tannins essentially and a non-negligible antioxidant activity. These metabolites are none other than phenolic compounds which are therefore corroborated and attest to the therapeutic properties traditionally granted to this plant. Histochemical studies of $H$. formicarum showed a high concentration of natural antioxidants in the central cylinder, particularly in the vascular bundle, whereas condensed catechic tannins were mainly detected

\begin{tabular}{|c|c|c|c|c|}
\hline $\begin{array}{l}\text { Metabolites Type } \\
\text { Studied }\end{array}$ & Test & Positive Colorimetric Reaction & Tissue Reacting Positively & Result \\
\hline Lipids & Soudan III & Bright red & Superior parenchyma & + \\
\hline Gums & Hematoxylin & Purple & $\begin{array}{c}\text { all the pectocellulosic walls are colored in } \\
\text { violet so no discrimination }\end{array}$ & - \\
\hline Sugars & Thymol $\mathrm{H}_{2} \mathrm{SO}_{4}$ (sulfuric acid) & Pink & Nothing to report & - \\
\hline Phenols & $\mathrm{FeCl}_{3}$ (iron chloride) & $\begin{array}{l}\text { Blue-black for tannin } \\
\text { green black for } \\
\text { phenols } \\
\text { green for flavonoids } \\
\text { red / blue for } \\
\text { pyrogallol }\end{array}$ & $\begin{array}{l}\text { Fibers, hypodermis and xylem walls ( } \\
\text { green) }\end{array}$ & ++++ \\
\hline Starch & lodine/Lugol & Blue-black & Nothing to report & - \\
\hline Flavonoids & $\mathrm{KOH}$ & Yellow & Epidermis, fibers, xylem & ++++ \\
\hline Coumarins & Ammoniac/alcoholic potash & Bright yellow & Nothing to report & - \\
\hline Catechic Tannins & $\mathrm{HCl}$ & Red brown & Collenchyma, fibers, xylem & +++ \\
\hline Alkaloids & Dragendorff & Orange & Vascular bundle (phloem) & + \\
\hline $\begin{array}{l}\text { Terpenes (Essential } \\
\text { Oil) }\end{array}$ & Phosphomolybdic acid & Black on yellow background & Cortical and central parenchyma & ++ \\
\hline Essential Oil & Soudan III/Chloral hydrate & Brown orange / red & Nothing to report & - \\
\hline Iridoides & $\mathrm{H}_{2} \mathrm{O}$ (hot) $+\mathrm{HCl}$ & Blue & Nothing to report & - \\
\hline Carotenoids & $\mathrm{H}_{2} \mathrm{O}+\mathrm{HCl}+\mathrm{H}_{2} \mathrm{SO}_{4}$ Lugol & $\begin{array}{l}\text { Green-blue } \\
\text { Green-blue }\end{array}$ & Nothing to report & - \\
\hline $\begin{array}{l}\text { Heterosides } \\
\text { Cardiotonic }\end{array}$ & $\begin{array}{c}\text { Raymond }+5 \text { drops of } \mathrm{KOH} \\
\text { Kedge }\end{array}$ & $\begin{array}{c}\text { Fugitive violet } \\
\text { (cardenolides) } \\
\text { Blue (lactonic genus) } \\
\text { Stable red }\end{array}$ & Nothing to report & - \\
\hline Antioxidants & DPPH & Decoration on purple background & Central cylinder (vascular bundle) & ++++ \\
\hline
\end{tabular}

+: positive reaction (graduation of 1 to 5 crosses for a qualitative evaluation of the colorimetric reaction); -: negative reaction

Table 1: Results of specific histolocalisation qualitative analyzes performed on transverse sections of Hydnophytum formicarum leaf. 
Citation: Babili FE, Guillouty A, Barbora HL, Vincent C, Sejalon-Delmas N (2017) Pharmacognostic, Phytochemical and Antioxidant Studies of Hydnophytum formicarum L. Med Chem (Los Angeles) 7: 276-284. doi: 10.4172/2161-0444.1000468

\begin{tabular}{|c|c|}
\hline Type of Hydnophytum ethanolic extract & DPPH assay $\mathrm{IC}_{50}(\mathrm{mg} / \mathrm{L})$ \\
\hline Ethanolic extract & $0.04 \pm 0.2$ \\
\hline Hexane fraction & $0.08 \pm 0.025$ \\
\hline Acetate ethyl fraction & $0.37 \pm 0.003$ \\
\hline Methanol fraction & $0.56 \pm 0.012$ \\
\hline Aqueous fraction & $0.08 \pm 0.001$ \\
\hline Trolox & $0.08 \pm 0.2$ \\
\hline
\end{tabular}

Table 2: Ethanolic extracts antioxidant activity.

\begin{tabular}{|c|c|c|c|}
\hline Hydnophytum & $\begin{array}{c}\text { Polyphenols } \\
\text { (eq Gallic acid) }\end{array}$ & $\begin{array}{c}\text { Tannins } \\
\text { (eq Catechin) }^{\mathbf{a}}\end{array}$ & $\begin{array}{c}\text { Flavonoids } \\
\text { (eq Quercetin) }^{\mathbf{a}}\end{array}$ \\
\hline $\begin{array}{c}\text { Aqueous fraction of the ethanolic } \\
\text { extract }\end{array}$ & $459.19 \pm 10.63$ & $30.52 \pm 6.56$ & $2.08 \pm 0.1$ \\
\hline
\end{tabular}

a: $g / K g$ dry; $:$ : $\mathrm{mg} / \mathrm{Kg}$ dry

Table 3: Composition of Hydnophytum extracts.

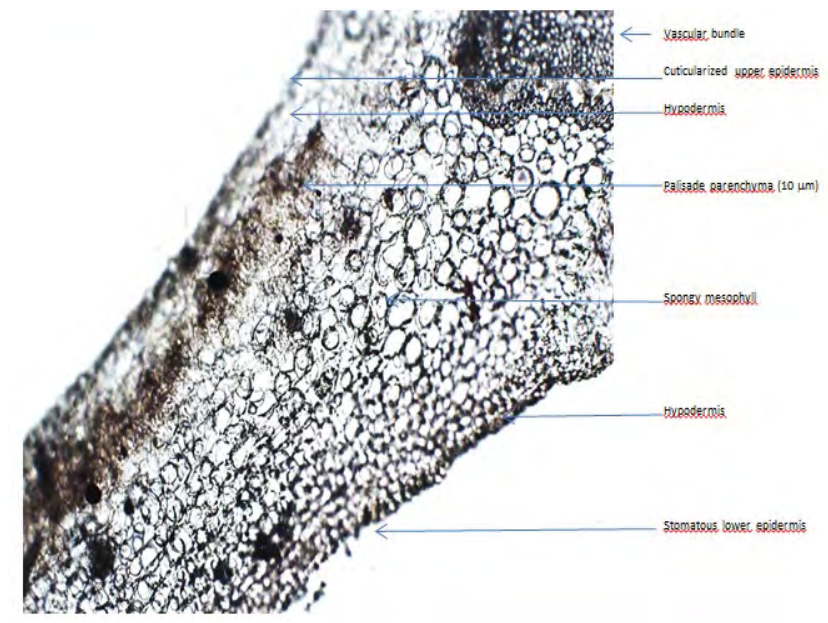

Figure 7: Transverse section of Hydnophytum formicarum leaf blade (magnification $\times 10$ ).

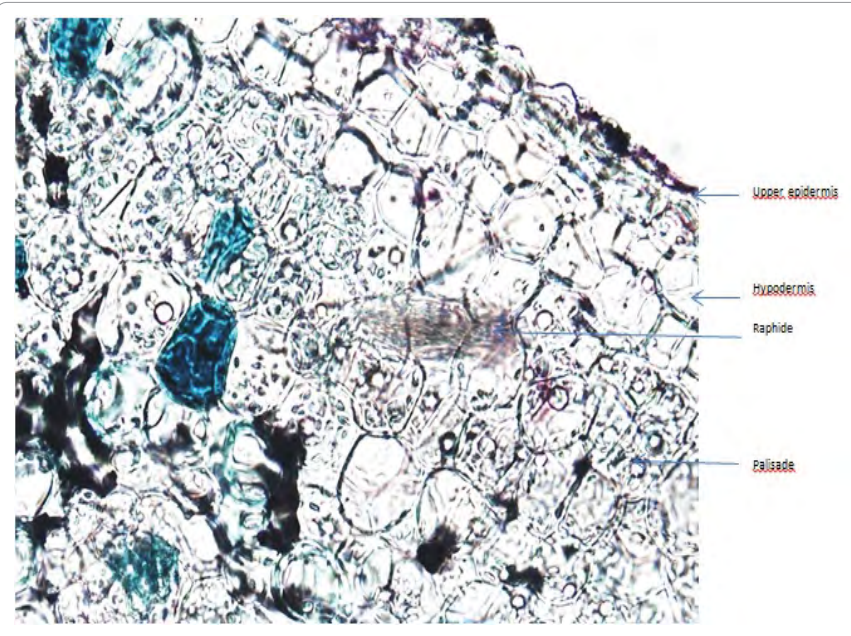

Figure 8: Transverse section of Hydnophytum formicarum leaf limb: (magnification $x$ 40) Raphides (scale bars: $7.5 \mu \mathrm{m}$ ) in the upper epidermis.

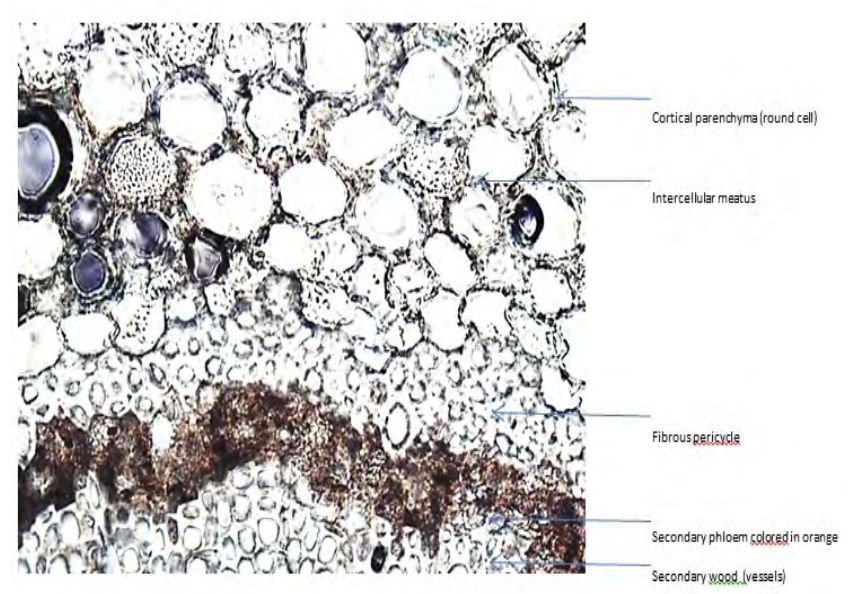

Figure 9: Histolocalization of alkaloids present in leaves transverse section of Hydnophytum formicarum leaf (magnification x 40): Dragendorff reagentstained CT.

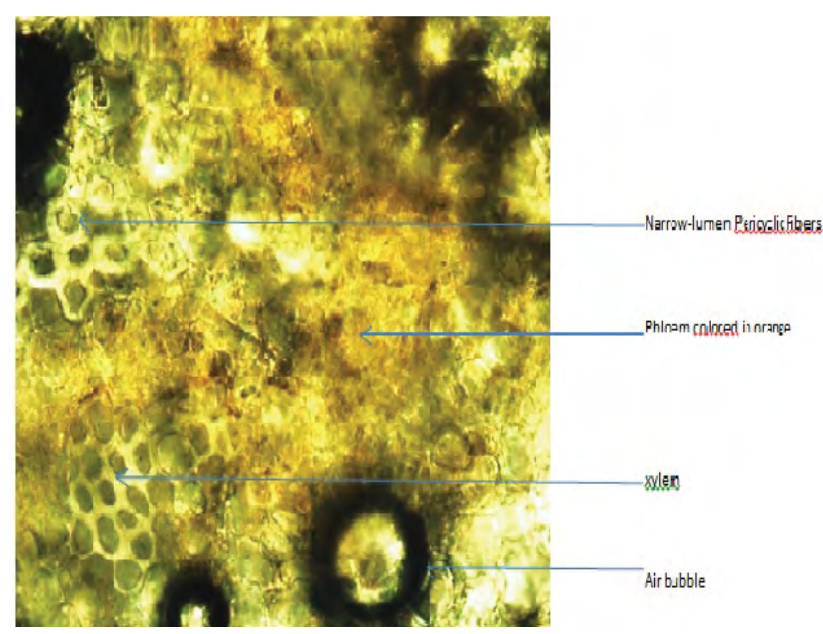

Figure 10: Transverse section of Hydnophytum formicarum leaf (magnification $\mathrm{x}$ 40) reacted for $5 \mathrm{~min}$ in Dragendorff reagent (Scale bar: vessel $1.25 \mu \mathrm{m}$ ). 


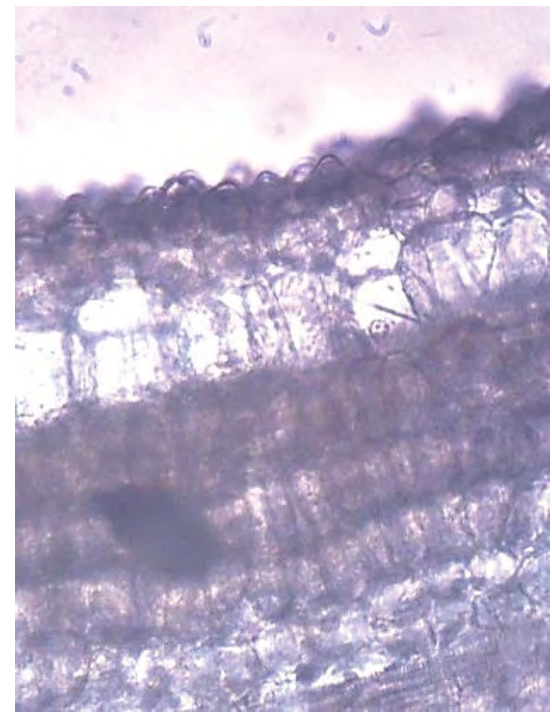

11a: Upper epidermis

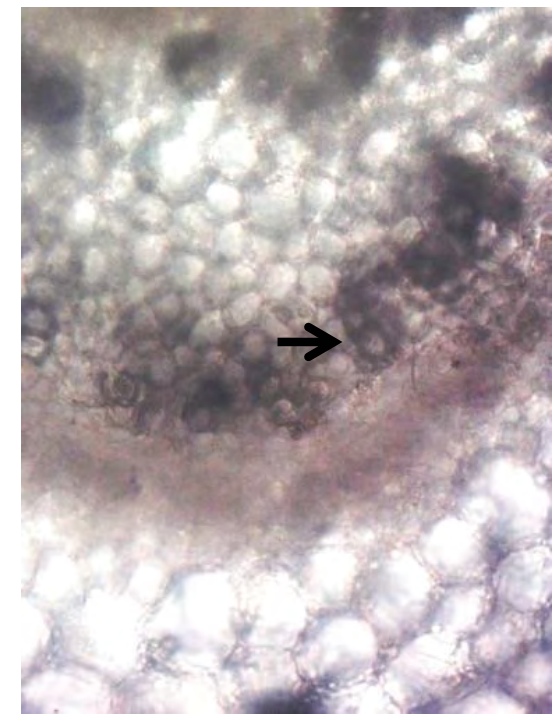

11b: vascular bundle

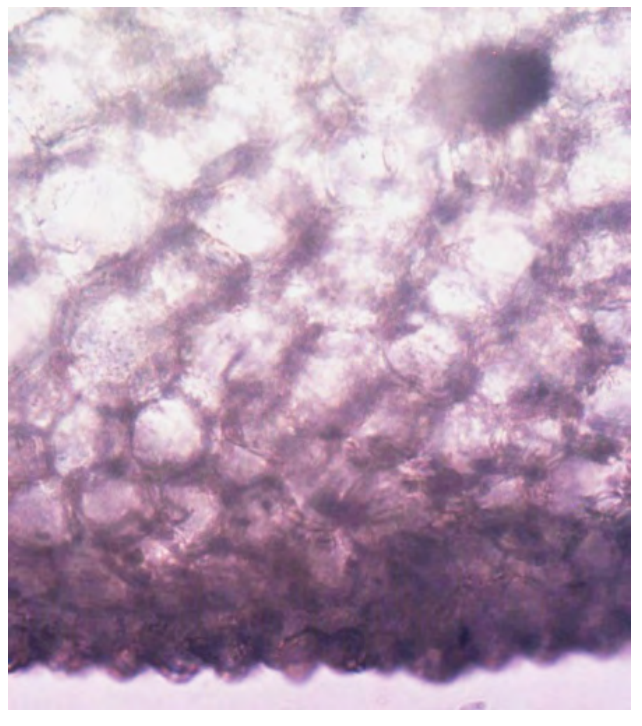

11c: Lower epidermis

Figure 11: Transverse section of Hydnophytum formicarum leaf (magnification x 400) reacted for 5 min in DPPH reagent.

in collenchyma, fibers and also in xylem. The high levels of phenolic compounds and their localization in the conductive tissues allow us to explain the traditional medicinal use carried out in Thailand with this tree because, very often, compounds with antioxidant properties prove to be good anti-cancer agents.

We have been able to show the usefulness of histolocalisation screening in order to make the initial research of medicinal plants (in particular antioxidant properties, see anticancer) more effective for a more complete phytochemical study, which can then lead to establishing the discovery of a new "structure-activity" relationship, in a further research.

Mother tincture, decoction and infusion were the commonly used form used in traditional medicine because of its ease. Indeed these traditional forms of plants medicinal consumption in the world, thus highlighting their health potential due to their high content of bioactive compounds possessing a variety of biological activities.

Antioxidants acting as radical scavengers are able to protect the human body as well as processed food from oxidative damage especially because of their wide application in food preservation. Due to their wealth of phenolic compounds (flavonoids, anthocyanins, carotenoids, etc.), numbers of plant extracts are used are usually used to add flavour and improve the shelf life of dishes and processed food products. The low cost of natural antioxidants and their beneficial properties increases the interest in polyphenol plants in order to develop their use in the food industry and preventive medicine. The antioxidant capacity measured by the DPPH assay is generally strongly correlated with the amount of total phenols, as shown by our results for Provence herbs [10], which are at the heart of a booming market. The alcoholic extract and the decoction, traditionally used methods, will be studied in our case because we want to demonstrate the correlation between the traditional use and the validated biological properties.

\section{Acknowledgements}

I especially thank the students of BTS in chemistry of the preparatory classes of the "Lycée de Déodat de Severac", in particular Mélanie Burliga, Mathilde Mouysset, Camilo Rojas and Mélissa Segatti, for their serious and applied work and their scientific curiosity.

\section{References}

1. Mirande R (1920) Sur le carmin aluné et son emploi, combiné avec celui du vert d'iode, en Histologie végétale. CR Acad Sci 170: 197-199.

2. European Pharmacopoeia (2015) Maison Neuve SA (ed.), Moulins, les Metz.

3. Speranza A, Calzoni GL (2005) Atlas de la structure des plantes. Belin, pp: 125-203.

4. Chen YM, Chen J, Mao GM, Fu JY (2007) Research on action of $R$. crenulata on anti-anoxia. Zhejiang Prev Med 1: 92-93.

5. Chen ZY, Chen YT, Wang DH (2006) HPLC determination of salidroside in the roots of Rhodiola plants. China J Chin Materia Medica 11: 939-941.

6. Rohfritsch O (1992) Etude de la structure du végétal à l'aide de techniques simples. Rev. Fr. Histotechnol 5: 31-35.

7. Wagner H, Bladt S, Zgainski EM (1984) Plant Drug Analysis a Thin Layer Chromatography Atlas. Springer-Verlag $\mathrm{GmbH}$, Berlin, Heidelberg, pp: 5-51, 145-163, 195-299.

8. Johansen DA (1940) Plant microtechnique. New York. McGraw-Hill.

9. Yoder LR, Mahlberg PG (1976) Reaction of alkaloids and histochemical indicators in laticifers and specialized parenchyma cells of Catharantus roseus (Apocynaceae). American Journal of Botany 63: 1167-1173.

10. Faure G (1914) Manuale di microgra ${ }^{\circledR}$ a Šegetale. Roma: Medico Farmacologico Ed.

11. Babili FE, Babili MEL, Souchard JP, Chatelain C (2013) Culinary Decoctions: Spectrophotometric Determination of Various Polyphenols Coupled with their Antioxidant Activities. Pharmaceutical Crops 4: 15-20.

12. Blois MS (1958) Antioxidant determinations by the use of a stable free radical Nature 181: 1199-1150.

13. Prachayasittikul S, Buraparuangsang $P$, Worachartcheewan $A$, IsarankuraNa-Ayadhya C, Ruchirawat S, et al. (2008) Antimicrobial and Antioxidative Activities of Bioactive Constituents from Hydnophytum formicarum Jack. Molecules 13: 904-921.

14. Nguyen MT, Awale S, Tezuka Y, Tran QL, Watanabe H, et al. (2004) Xanthine oxidase inhibitory activity of Vietnamese medicinal plants. Biol Pharm Bull 27: 1414-1421.

15. Darwis D, Hertiani T, Samito E (2014) The effects of Hydnophytum formicarum ethanolic extract towards lymphocyte, vero and T47d cells proliferation in vitro. J App Pharm Sci 4: 103-109.

16. Senawong T, Misuna S, Khaopha S (2013) Histone deacetylase (HDAC) 
Citation: Babili FE, Guillouty A, Barbora HL, Vincent C, Sejalon-Delmas N (2017) Pharmacognostic, Phytochemical and Antioxidant Studies of Hydnophytum formicarum L. Med Chem (Los Angeles) 7: 276-284. doi: 10.4172/2161-0444.1000468

inhibitory and antiproliferative activities of phenolic-rich extracts derived from the rhizome of Hydnophytum formicarum Jack.: sinapinic acid acts as HDAC inhibitor. BMC Complementary and Alternative Medicine 13: 232.
17. Hertiani T, Pratiw SUT (2015) Hydnophytum formicarum Jack ethano extract modulates quorum sensing-controlled pathogenicity in Pseudomonas aeruginosa ak. J Pharm Sci 28: 1691-1697. 